\title{
LUGARES Y REDES. LAS MEDIACIONES DE LA CULTURA URBANA
}

\author{
Michel Agier* \\ Traducción de Andrés Salcedo Fidalgo, \\ revisada por Leonor Herrera
}

* Director de investigación del Instituto Francés de Investigación Científica para el Desarrollo en Cooperación (ORSTOM, Paris) y profesor asociado de la Escuela de Altos Estudios en Ciencias Sociales (EHESS, Marsella)

Revista Colombiana de Antropologia, vol XXXII. 1995 
Research into the relative significance applied to a reas of a city tells us about urban identities; the study of social connections tells us about the cultures responsible for attachment to urban places and also about the reproduction or reinvention of social links in the dense, open and heterogeneous environments of contemporary societies. The popular suburb of Liberdade in San Salvador de Bahia (Brazil) is taken as a case study from these two points of view. It is a proletarian black suburb, densely populated and lively, both welcoming and threatening, conservative and - paradoxically - with a strong urban tradition: antiquity, permanence and stability are other concepts associated with it. The study attempts to determine which social bonds are responsible for the feeling of attachment to this place on the part of its inhabitants; or, put another way, how social identity is created. It seeks the source of identities linked to certain parts of the city, which define an individual as a person, and using the concept of the network attempts to determine the type of culture created by the world of urban relationships.

\section{EL INDIVIDUO, LA CIUDAD, LA ANTROPOLOGIA}

Para los etnógrafos y sociólogos de la Escuela de Chicago, la ciudad era el mundo del individuo. Una línea de investigación, importante y durable, se constituyó entonces en torno al tema del individualismo urbano - Louis Wirth hablaba de anomia. El punto de partida de estas investigaciones fue sin duda una concepción errónea del mundo rural, entendida como referencia y réplica de la ciudad. En efecto, la problemática del modo de vida urbano se fundó sobre una dicotomía particular, que contraponía la sociedad urbana a la sociedad tradicional.

Es así como Robert Ezra Park, el inspirador de la Escuela de Chicago, veía en la ciudad el sitio del "surgimiento del individuo como unidad de pensamiento y de acción" (Park, 1929/1979:165) y, al mismo tiempo, se preguntaba cómo actualizar, en la ciudad, la referencia "comunitaria" del enfoque 
holistico idealizado del mundo rural. Propuso en estos términos una problemática que se puede pensar, fue la fundadora de las investigaciones de la Escuela de Chicago:

El problema social es fundamentalmente un problema urbano. Se trata de llegar, dentro de la libertad propia de la ciudad, a un orden social y a un control social equivalentes a aquello que se ha desarrollado naturalmente dentro de la familia, el clan, la tribu (Park 1929/1979:164).

Dónde se lleva a cabo, entonces, el control social urbano? Para responder, Park desarrolla una aproximación llamada ecológica. El habla, primero, de "áreas naturales de segregación". Cada área tiene su función de distribución de la población. Observa que sectores de distribución y simultáneamente de segregación se determinan, en Chicago, según el origen (migrantes), la etnia, la edad, el tipo de organización familiar, etc. Park propone considerar estas áreas como el hábitat natural (en el sentido ecológico) del "hombre civilizado" (el citadino) opuesto al "hombre primitivo". Progresivamente, en el texto de Park, esas áreas se transforman en "medios morales" y en "regiones morales". Estas nociones, primero reservadas a áreas moralmente diferentes o separadas del resto de la ciudad (barrios de prostitución o de bohemia), van a extenderse a todo el espacio urbano segregado. Esto es lo que va finalmente a matizar la hipótesis individualista inicial:

En una sociedad tal, el individuo se convierte en una persona: una persona no es otra cosa que un individuo que, en cualquier lado, en un medio cualquiera, tiene un status social; pero dicho status resulta ser en últimas un asunto de distancia - de distancia social (Park 1926/1979:206).

En este punto del análisis, se podría - como se tratará de hacer enseguidabuscar los significados relativos que distinguen ciertos espacios dentro del conjunto de una ciudad, para comprender las fuentes de identidades que se encuentran ancladas en ella y que definen una parte de esta "persona" a la cual se refiere Park en la cita anterior. Volveremos sobre este punto más adelante y ese será el primer tema de nuestra reflexión sobre el sentido de los lugares urbanos. Pero sigamos primero a Robert Park cuando, después de haber aprehendido la ciudad bajo la óptica de la segregación y de las regiones morales, vuelve a su hipótesis del principio, la del individuo. La figura del citadino se construye entonces recurriendo a metonimias del intersticio -como la calle,

De ahi viene la noción de "ecologia urbana" que ha servido para caracterizar a este grupo de investigadores de la Universidad de Chicago de los años 1920 a 1930. 
el 'deambular', o el tráfico - o a tipos sociales de intermediación - el paseante, el extranjero, el rebusque y el 'tejemaneje'. Por consiguiente, los repertorios del citadino se conforman en las márgenes, recobrando de este modo, en teoría al menos, un poco de su libertad ${ }^{2}$. Para entender la ciudad a la vez como segregada y como el ámbito del individuo y del libre albedrío, Park tiene que recurrir a una noción y a una imagen. La noción es la de movilidad, la imagen es la del mosaico:

Fuera de los transportes y las comunicaciones, es la segregación misma la que tiende a facilitar la movilidad de los individuos. Los procesos de segregación instauran distancias morales que hacen de la ciudad un mosaico de pequeños mundos que se tocan sin interpenetrarse. Esto le da a los individuos la posibilidad de pasar fácil y rápidamente de un medio moral a otro y estimula esta experiencia fascinante, pero peligrosa, que consiste en vivir en numerosos mundos diferentes, efectivamente contiguos y sin embargo, bien diferenciados (Park 1925/1979:121).

La metáfora del mosaico ha sido utilizada frecuentemente para describir la ciudad. Ella proviene, en el fondo, del mismo proceder que tiene la antropología y que criticará más tarde la Escuela de Chicago, contraponiéndole la figura de los "énclaves" para referirse a los espacios urbanos. Nada prueba, en efecto, que los mundos urbanos estén caracterizados de manera tan hermética como lo entiende Park, y sin duda él reproduce el mismo error que sus críticos más virulentos, como Oscar Lewis por ejemplo, que no ven como verdaderas mediaciones sociales para los ciudadanos, más que las que toman la forma de grupos estructurados y espacializados, remitiendo al paradigma del ghetto ${ }^{3}$. De hecho, Park utiliza un pensamiento individualista y una referencia socioespacial holística, partiendo de un modelo alternativo y complementario y separando los dos momentos del enfoque. Este dualismo excluye la ambivalencia, no permite dar cuenta de la dinámica de lo social y reduce su comprensión a

2 Estos diferentes enfoques son desarrollados o analizados por Hannerz (1983), Simmel (1908/1979), Grafmeyer y Joseph (1979), Joseph (1983 y 1984). Dentro de esta perspectiva de investigación, Hannerz (1983:140) va a diferenciar dentro de la ciudad, ciertos dominios considerados "más urbanos" que otros: los del espacio público, los del mercado, los del tráfico, etc. Se vuelve a encontrar esta dualidad dentro de la distinción hecha, más recientemente, por I. Joseph (1995:9) entre la aproximación a la ciudad desde los espacios domésticos y desde los espacios públicos, éstos últimos considerados como los lugares del surgimiento de una cultura propia de la ciudad.

3 Las descripciones de las vecindades de Mexico y del barrio Esmeralda en Puerto Rico (Lewis 1963 y 1969) -características de la impresión del cierre físico y social inherente en la forma como están escritas - sirven de contexto "comunitario" para el estudio de familias urbanas. 
soluciones idiosincrásicas. Esta ruptura del análisis entre un referente individual móvil (y abierto) y un referente social fijo (y cerrado) se hace aún más explícita cuando Park se aventura en el diagnóstico de problemas sociales:

De hecho, la mayoría de nuestros problemas habituales de comportamiento son efectivamente resueltos, cuando tienen una solución, transfiriendo al individuo de un entorno donde se comporta mal a uno donde se comporta bien (Park 1929/ 1979:172)

Para poder pensar la ciudad de manera global, sin perder de vista su individualismo emblemático y su heterogeneidad (social, racial, cultural, etc), la antropología debe, primero que todo, me parece, despojarse del $a$ priori de la referencia espacial ${ }^{4}$. Para llevar a cabo dicha ruptura desde su misma tradición, esta disciplina puede acudir al análisis de redes, concebido precisamente para dar cuenta de las relaciones urbanas. Los investigadores de la Escuela de Manchester en el Rhodes Livingstone Institute quisieron salirse de los enfoques llamados "estructural-funcionalistas", juzgados inadecuados para tener contacto con las ciudades y con sus "sociedades de pequeña escala donde faltaban caracteres estructurales" (Mitchell 1969:9). Para ellos, las redes se convirtieron en sinónimos de movilidad, de comunicación entre diversos medios y de cambio cultural. Las redes no se oponían sin embargo a la idea de estructura. De esta forma, Hannerz (1983) definió la ciudad como "la red de redes". A pesar de que conviene subrayar que se trata aquí de una visión más metafórica que realista, el espacio urbano pudo así ser interpretado como un conjunto articulado y los medios sociales urbanos como sistemas solidarios e incluso como sistemas casi "mafiosos". Barnes (1969), por su parte, introduce la noción de "red total" para circunscribir el conjunto de redes en una situación dada. Finalmente, la red total recompone la estructura o, como lo sugiere Mitchell (id:49), las redes atraviesan las instituciones. No se sabe, sin embargo, si recomponen el sentido y cómo lo hacen. Esto es precisamente lo que se quiere buscar, como segundo tema de reflexión, en el caso del barrio Liberdade en Salvador: ¿cuál es la cultura que crean los mundos relacionales urbanos?

$4 \quad$ Este a priori hace parte de la ilusión monográfica, esa que presupone la transparencia de sentido entre un espacio, una sociedad, una cultura y un tipo de individuo. En Augé (1992:57-95) se encuentran algunos desarrollos sobre las diversas formas de concebir el "lugar antropológico"

5 La ciudad de San Salvador de Bahía es la capital del estado de Bahía en Brasil (N. del T.). 


\section{LIBERDADE (BAHIA): IMAGENES CRUZADAS}

De aceptarse lo anterior, se puede admitir que la antropología urbana es una de las modalidades de esa antropología paradójica que pone al individuo en el centro de su problemática, cuando no de sus respuestas (Augé 1994). Se pueden entonces diferenciar dos momentos en el análisis, que desde la observación se presentan como un conjunto. En primer lugar, la investigación sobre las significaciones relativas que se le dan a los espacios de la ciudad nos informa sobre las identidades urbanas. En segundo lugar, el estudio de las sociabilidades nos informa sobre las culturas que conforman el apego a los lugares urbanos y también sobre la reproducción o la reinvención de los lazos sociales en los universos densos, abiertos y heterogéneos de las sociedades contemporáneas. El barrio popular de Liberdade, en Bahía, se presta para esta reflexión en dos momentos.

Demográficamente denso, con 130.000 habitantes actualmente, principalmente negros y mestizos, distribuidos en los diversos estratos sociales bajos y medios (trabajadores informales, asalariados de nivel bajo, empleados de empresas antiguas o más recientes, desempleados, lavanderas y empleadas domésticas, etc) el barrio Liberdade se encuentra así mismo repleto de interpretaciones heterogéneas. En los años treinta la municipalidad - nacionalista, a la usanza del momento- bautizó la calle con el nombre de "Estrada da Liberdade" (Ruta de la Libertad) en recordatorio de la entrada en 1823 de las tropas independentistas que liberaron al Estado de Bahía del yugo portugués, precisamente por la arteria principal del barrio, nombre que se extendió colectivamente a los barrios aledaños. En los años cuarenta Jorge Amado se autodenominaba el poeta del "barrio más populoso y proletario de la ciudad de Bahía" (Amado 1982: 81). Describía con horror "la miseria oriental de los barrios trágicos" de Liberdade, trayendo a cuenta los nombres evocadores de los sectores de Japão, Mandchuria o Changai (Amado 1982: 82). Finalmente, veía en dicho barrio el símbolo de la lucha proletaria por la resistencia y por la "Liberdade". En los años cincuenta otro guía erudito de la ciudad de Salvador se refería también a la Estrada da Liberdade como un lugar de búsqueda de la libertad popular. Pero en medio de los "tugurios", entre el polvo y el lodo (Brandão y Motta 1958:174), quien es exaltado es el Negro que canta, baila, ruega o entra en transe, así como "las bellas negritas con turbante rosa en los cabellos, que se pasean cogidas de la mano de sus elegantes enamorados en terno blanco, como si la via fuera verdaderamente la de la libertad" (Brandão y Motta 1958: 175). Por último, en los años setenta Liberdade fue el sitio donde los jóvenes Negros, con alguna educación formal, que comenzaban a trabajar en las empresas nacientes del polo petroquímico de Bahía, inventaron 
la comparsa carnavalesca Ilê Aiyê. Se desarrolló allí un discurso culturalista y político - africanista y negro. Liberdade se convirtió entonces en sinónimo de quilombo (palenque) con sus sitios de aspecto étnico tales como la "senzala do barro preto" ", la "calle Kingston" (sitio de las veladas de otra comparsa afro, Muzenza, creada en 1981), o la plaza del Plano inclinado (principal sitio de fiestas del barrio) rebautizada en 1992 "Plaza Nelson Mandela".

Es así como un nuevo significado viene a sumarse a otros más antiguos, consolidando de este modo una premisa de base para la identidad del barrio: como quiera llamársele, es todavía un sustrato social local señalado como sujeto, movilizado, reunido, interpelado: el de "la gente de la Liberdade". Hay un sentimiento de arraigo al barrio, un orgullo de ser de ahí, incluso para quienes, en situaciones de movilidad social, lo han abandonado (véase Agier 1990). En Salvador, el barrio de Liberdade está asociado a todas las imágenes que acabaron de evocarse brevemente; está así mismo asociado a la idea de una cierta antigÜedad, permanencia y estabilidad, incluso para los más pobres ${ }^{7}$ gracias a esa acumulación de calificativos. En una ciudad como Bahía, que se transformó notoriamente en los últimos decenios y que en el censo de 1991 ocupaba el tercer lugar del país dado su tamaño (2.072.058 habitantes), Liberdade sería uno de los sitios de tradición urbana por excelencia. Es necesario partir de la paradoja que encierra la expresión anterior - recuérdese que Park, uno de los fundadores de la antropología urbana, oponía la sociedad urbana a la sociedad tradicional- - para preguntarse cuáles son los lazos sociales que fundamentan este sentimiento de arraigo al lugar, o dicho de otra manera, cómo se construye esta identificación social que toma los nómbres del lugar como marcadores de identidad. Se verá que es necesario franquear diferentes imágenes y fronteras sucesivas antes de encontrar los pequeños mundos relacionales que conforman el barrio y le dan sentido.

De una calle que atraviesa todo el barrio a lo largo de un poco más de dos kilómetros (L'Estrada da Liberdade) y que sirvió durante varios decenios como vía del tranvía que conectaba a todo el barrio con el centro de la ciudad, se desprenden las entradas de por lo menos una veintena de sectores de este ba-

6 Literalmente "la casa del esclavo en tierra negra", es un terreno baldio donde se realizaron las fiestas del Ilê Aiyê de 1976 a 1987.

7 La antigüedad de los barrios populares intra muros explica la existencia de una pobreza relativamente más estable en la ciudad que en su periferia. Generalmente, en las grandes metrópolis brasileras, las condiciones de vivienda de los más pobres (tipo de construcción, acceso al agua y al alcantarillado) son, tomando un nivel de ingresos igual, mejores en los centros urbanos que en las periferias (Ribeiro y Lago 1994:275) 
rrio. El conjunto de estos espacios ocupa un paisaje de colinas, construcciones por debajo del nivel de las calles, rampas y escaleras ${ }^{8}$.

La identificación de sus habitantes se hace de manera alterna: para los de afuera, se denominan habitantes de Liberdade, conocido en la ciudad como el barrio negro y proletario, populoso y animado, acogedor pero a la vez temido y, para algunos, vedado? . Dentro de esta primera identificación contrastante se crean otras fronteras imaginarias internas a través de los nombres y los límites de los sectores del barrio o calles de residencia. Cada nombre de sector (que según el caso abarca 2.000 a 5.000 habitantes aproximadamente) adquiere un sentido dentro de la historia específica del sitio denominado. Por ejemplo, el sector de Sieiro debe su nombre a un comerciante español apellidado así, quien llegó a principios de los años veinte y abrió un almacén que servía como punto de referencia para los extranjeros y paradero del tranvía: "Almacén Sieiro". El tranvía ya no existe. El almacén fue vendido sucesivamente, después transformado en bar y finalmente perdió su nombre original. Pero el nombre se sigue usando para denominar los alrededores inmediatos. Estas identidades están muchas veces asociadas a algunos rasgos específicos que pueden, según la ocasión, repercutir en buen o en mal sentido en todo el conjunto de Liberdade, que se torna, en este caso, en una "región moral" como la entendía Park originalmente. De esta forma, la calle Curuzu se percibe, desde hace unos quince años, como el núcleo del movimiento negro en la ciudad ${ }^{10}$, hasta el punto que el MNU (Movimiento Negro Unificado) de Bahía instaló su sede en esta calle —dándole un carácter incluso más "étnicc". En otro registro moral, la Avenida Peixe (un callejón sin salida con construcciones bajo el nivel) es identificada como la guarida de los "marginales" del barrio. Esta estigmatización puede estar reforzada por los habitantes de las zonas contiguas, dado que un cierto ascenso social los incita a excluirse de una imagen negativa atribuida, desde afuera, al barrio Liberdade en su conjunto y con tal de reservar dicha imagen a sólo una parte del barrio solamente, concentran sobre ella toda la mala reputación. Esto se percibe en las palabras de un habitante de Liberdade (en el

8 El lector colombiano puede imaginarse a Liberdade muy parecida a la ciudad de Manizales (N. del T.).

9 Un lider de la comparsa carnavalesca afro Ilê Aiyê declara, por ejemplo: " he estado siempre orgulloso de ser de la Liberdade. En otra época habia tranvia, las líneas del tranvía estaban clasificadas por números. La Liberdade es el número 8 . Habia música y todo eso. si alguien te molestaba, no importaba quien, decias que eras de la línea 8 , de la Libertade, y la gente te trataba siempre con un cierto respeto" (Antonio Carlos dos Santos Vovo, fundador de la comparsa Ilê Aiyè)

ii) Es ahi donde nació la comparsa carnavalesca afro Ilè Aiyê 
sector próximo a la Avenida Peixe); obrero asalariado y joven padre de familia, quien vive en un apartamento de dos alcobas alquilado, a algunos metros de la casa paterna donde nació. En 1993, cinco años después de la entrevista relatada enseguida, ya no era obrero sino chofer de taxi y vivía todavía en el mismo sitio:

Yo no me he mudado todavía porque no he encontrado un sitio adecuado donde vivir. Porque yo no admito que uno se vaya a cualquier lado, a pagar menos para vivir en un mal sitio. Que no es el sitio de uno. Por ejemplo: encuentro una casa en Pero Vaz, allá en la baixada do Pero Vaz [otro nombre para designar la Avenida Peixe], mil quinientos cruzados, dos cuartosestar-cuarto de baño. Lo compro. Muy bien. Es mío. Pero creo que no haría un buen negocio porque voy a vivir con los marginales. No estaría seguro, cuando saliera a trabajar mi familia no estaría segura. Porque yo sé que ahí hay muchos marginales. Mis hijas no van a poder estar en la calle, no tendrán libertad. Se volverían como personas que han sido criadas en prisión. Se volverían niños rebeldes. Entonces esto no traería más que cosas malas. Porque ellas no conocen nada de la vida, cuando salgan van a encontrar que... nadie hace el bien, todo el mundo hace el mal. Los malos consejos. Y a partir de ahi, el resultado no es más que eso, marginalidad. Es por eso que no tengo ganas de ir a un sitio de ese tipo. Al menor robo que tiene lugar por aquí en los alrededores, usted puede ir a la Avenida Peixe y encontrará a todo el mundo allá. Eso allá es conocido tanto como la Baixada Fluminense en Río de Janeiro. Allá la gente presiona a las personas a robar" "1.

Todos estos sectores de Liberdade están constituidos por un tejido denso de callejuelas, de callejones sin salida y de callecitas peatonales estrechas, que contrasta con el aspecto más abierto y manifiesto de calles pavimentadas y con mucho tránsito (adyacentes a la Estrada da Liberdade) y de las pequeñas plazas centrales (generalmente al final de las rutas de autobus). El sentimiento de pertenencia a cada uno de los sitios se refleja en la identificación que se tiene por Liberdade desde fuera, frente al resto de la ciudad. Es dentro de esta dimensión que aparecen los sentimientos de "ser de la Liberdade" entonados en las sambas de la comparsa carnavalesca Ilê Aiyê o en las interpelacines de "pueblo de la Liberdade" o "comunidad de la Liberdade", utilizadas por los políticos.

11 Esta diatriba contra un sector aledaño puede ser objeto también de una segunda interpretación, complementaria: dado que el que habla es uno de los lideres de la vida de las turmas (bandas) locales (véase más adelante), se puede pensar que está expresando aqui una hostilidad bastante caracteristica a propósito de una "zona" vecina (véase Magnani 1984:139) 


\section{REPRESENTACIONES DEL ESPACIO Y CLASIFICACIONES FAMILIARES}

Dentro del sector que se estudiará ahora más en detalle (alrededor de 2.000 habitantes), el espacio se puede dividir entre la plaza central (el largo de $X$ que le da el nombre a dicho lugar) y sus calles pavimentadas adyacentes - la parte visible del sitio- por un lado, y por otro las callejuelas (avenidas), la parte invisible y mas íntima. La plaza y sus calles contiguas están ocupadas por casas antiguas (años 1920, 1930) con fachadas elegantes pero muy deterioradas. Algunas fueron enteramente transformadas y ampliadas entre los años cuarenta y sesenta. En este caso, pueden albergar varias generaciones de una misma familia repartidas en dos o tres niveles (el piso de abajo eventualmente ocupado por algún taller, tienda o bar). Algunos propietarios (ya sea, por herencia o por matrimonio) de casas de familia se volvieron patrones de negocios inmobiliarios. De este modo y desde comienzos de los años sesenta se contruyeron pequeños inmuebles de renta sobre el perímetro de la plaza central, en las calles adyacentes y a lo largo de algunas callejuelas que se desprenden de estas calles.

Las avenidas se formaron en los fondos de algunas de estas antiguas casas de familia. En este barrio, este tipo de vivienda se desarrolló principalmente a partir de los años cuarenta, período de migraciones intensas que llevaron a numerosas familias del vecino Recôncavo hacia el centro de Salvador, hasta saturar, hoy en día, prácticamente todo el espacio que se podía construir. Las avenidas se formaron gracias a acuerdos informales entre los habitantes de estas casas y quienes vinieron a ocupar los espacios vacíos situados detrás, a cambio de un arriendo; dicha ocupación seguía el patrón de las "invasiones" que se desarrollaron, desde la misma época, dentro de las zonas no habitadas de la ciudad y su periferia. Esta se convirtió, en algunos casos, en una práctica puramente inmobiliaria y en el barrio se conserva la memoria algunos nombres de familias conocidas por haber abierto, de esta forma, numerosas avenidas en lo que eran terrenos baldios del barrio. Así algunas de estas avenidas alberguen casas bonitas o incluso edificios angostos, están ocultas a la mirada y por ésto quedan marcadas con la huella de la pobreza.

La división entre la plaza y las aveniclas es el marco general de una clasificación social y familiar y al mismo tiempo, espacial. En efecto, a partir de este marco los habitantes distinguen en el barrio tres estratos sociales que de hecho son tres clases de familias. Se las presentará enseguida de manera resumida. 
Las familias llamadas "de la plaza" viven alrededor de la plaza central y en sus calles adyacentes. Estas familias son vistas, tradicionalmente, como las más acomodadas del barrio. Familias de comerciantes, de funcionarios de rango medio, de patrones de talleres o de pequeñas empresas de construcción, que ocupan la posición dominante dentro de la jerarquia local, a pesar de que, hoy en día ya no son ellas (o ya no son las únicas) que tienen los ingresos más elevados. Su posición se consolidó por medio de la acumulación de prácticas familiares, inmobiliarias y relacionales en las cuales el barrio era el marco de referencia. Toda familia "de la plaza" se caracteriza por el hecho de poder agrupar a un conjunto de parientes agnáticos (siblings.) con sus propias familias nucleares dentro de una sola casa o en una alineación de casas contiguas. Por otra parte, pueden ampliar sus grupos domésticos por medio de la acogida de agregados - parientes en línea ascendente y colateral, personas que no son parientes- y haciéndose cargo en forma regular de niños de crianza, criados en la casa hasta la edad adulta. Dentro de estas prácticas de asistencia y de caridad, se reproduce el dominio de estas familias sobre los segmentos más pobres de su parentela así como su dominación a nivel de la red social local.

Las familias "necesitadas" de las avenidas están en lo más bajo de la escala social local. Encabezadas en su mayoría de los casos por mujeres de status profesional precario, estos grupos domésticos sobreviven ${ }^{12}$ gracias a la intervención de una red de parientes localizados por fuera de la casa. Allí encuentran diversas formas de colaboración: pequeños empleos temporales, regalos de comida, albergue de niños, préstamos y regalos en dinero, ayudas para conseguir empleo, etc. Dicho de otro modo, no hay, en este caso, una adecuación exacta entre la casa y la familia. Hay, por el contrario, una repartición de las funciones familiares (residenciales, reproductoras y de socialización) dentro del espacio global familiar, localizado, al menos en parte, en el barrio de Liberdade o, más cerca aún, en el sector del largo ${ }^{13}$. La intervención de los otros estratos sociales del barrio en la reproducción de las unidades domésticas se realiza a través de relaciones familiares y muchas otras formas de protección de las casas (padrinazgo, lazos de estimación, circulación y cuidado de los niños, etc). La posición de las familias "necesitadas" de las avenidas en la estructura de relaciones sociales del barric, puede definirse entonces bajo dos puntos de vista. Según el punto de vista de las clasificacio-

12 Si se suman los ingresos de los diferentes miembros de la casa (cuando son varios miembros los que trabajan) no se llega nunca a los dos salarios minimos.

13 En el caso de una de las avenidas más pobres del barrio, se pudo establecer que las tres cuartas partes de las casas tenian parientes en el barrio de Liberdade, y que $56 \%$ de los padrinos y madrinas de los niños de la crenicla, vivian en Liberdade (Agier 1990b). 
nes, estas familias representan la condición social más desvalorizada y son consideradas por los otros habitantes del barrio como un polo negativo que agrupa todos los rasgos de una pobreza temida y rechazada. Desde el punto de vista de su integración y de su función dentro del sistema social local, su posición adquiere sentido a partir de redes personales y familiares ( $\mathrm{y}$ de valores morales involucrados en el funcionamiento de estas redes) que ligan o relacionan las diferentes clases de familias. Los favores que reciben aseguran su existencia social al tiempo que le dan status y poder a las familias que las están sosteniendo.

Las familias "equilibradas" de las avenidas están situadas entre lo alto y lo bajo de la jerarquía de status del barrio. Las avenidas donde viven son a veces amplias y algunas casas son incluso confortables, de varios pisos. A la entrada, se pueden ver, el domingo por la mañana, algunos hombres lavando su carro (comprado de segunda) mientras que otros, en el interior de la avenida, trabajan en la mejora de sus casas. Sus grupos domésticos son habitualmente autosuficientes y entre ellos se encuentra una proporción significativa de padrinos y madrinas de niños de las avenidas más pobres. Tienen así mismo parientes (hermanas, madre, cuñados) con quienes tienen que cumplir obligaciones de ayuda mutua. Tres elementos distinguen localmente a estas familias. El primero tiene que ver con el lugar que ocupan las identidades profesionales en la formación de su identidad familiar. Para estas familias que llaman familias de doqueiros (cargadores del puerto) de comerciários (empleados de comercio), de funcionários públicos y más recientemente de petroleiros (trabajadores de la compañía nacional de petróleo) y de petroquímicos (trabajadores del sector petroquimico), la taxonomía de estas categorías profesionales se vuelve un modo de clasificación social local: simboliza una integración social y una participación política envidiables, logradas en un universo de trabajo exterior al universo del barrio. En segundo lugar, la estabilidad relativa de estos hogares en términos de empleo y de ingresos permite que allí se desarrolle sin mayores aprietos el conjunto de los ciclos familiares sucesivos (constitución, expansión, substitución). Dicho de otro modo, el éxito profesional y económico de los jefes de familia de este grupo intermedio se vuelve visible en términos de "éxito" matrimonial. Su organización doméstica se torna así modelo del equilibrio para los que le rodean. Es interesante anotar aquí un tercer elemento que caracteriza a estas familias: el hombre asume su rol de proveedor de las necesidades del grupo, capaz de darle estabilidad y capaz de ampliar la unidad doméstica, la cual superará progresivamente los límites de la familia conyugal. Se pudo en efecto registrar, en el curso de una encuesta en tres avenidas del barrio que las unidades domésticas cuyo jefe es un hombre tienden a expandirse por medio de la acogida de parientes colaterales, personas que no son parientes y niños nacidos por fuera del matrimonio - tendencia 
realizada ampliamente en las familias "de la plaza" (véase el siguiente cuadro). La familia nuclear stricto sensu engloba dos tercios de los miembros de estos grupos domésticos y el tercio restante está formado por niños nacidos fuera de la relación de pareja $(10,2 \%)$ y por un conjunto de agregados (más del $20 \%$ ): hijos pequeños, parientes colaterales, y personas que no son familiares ${ }^{14}$. Todas estas prácticas son interpretadas por los jefes de familia como el resultado de imposiciones familiares o como muestras de generosidad.

Composición de las unidades doméstica según el sexo del jefe de familia (Liberdade, sector del Largo, 1988)

RELACION

CON EL J.F.

Jefe de familia

Cónyuge

Niños del JF

Niños del cónyuge

Niños de la pareja

Niños de hijas

Niños de hijos

Ascendientes del JF

Asend. del cónyuge

Colaterales del JF

Colat. del cónyuge

yernos y nueras

No-familiares

TOTAL

TAMAÑO PROMEDIO

DE LAS UNIDADES

DOMESTICAS

\section{J.F. HOMBRE}

No $\%$

J.F. MUJER

Total

No $\%$

No $\%$

$\begin{array}{cccccc}35 & 18,9 & 23 & 21,7 & 58 & 19,9 \\ 32 & 17,3 & 2 & 1,9 & 34 & 11,7 \\ 8 & 4,3 & 41 & 38,7 & 49 & 16,8 \\ 11 & 5,9 & 0 & - & 11 & 3,8 \\ 61 & 33,0 & 4 & 3,8 & 65 & 22,3 \\ 9 & 4,9 & 17 & 16,1 & 26 & 8,9 \\ 1 & 0,5 & 2 & 1,9 & 3 & 1,0 \\ 0 & - & 3 & 2,8 & 3 & 1,0 \\ 2 & 1,1 & 0 & - & 2 & 0,7 \\ 11 & 5,9 & 12 & 11,3 & 23 & 7,9 \\ 5 & 2,7 & 0 & - & 5 & 1,7 \\ 2 & 1,1 & 1 & 0,9 & 3 & 1,0 \\ 8 & 4,3 & 1 & 0,9 & 9 & 3,1 \\ 185 & 100,0 & 106 & 100,0 & 291 & 100,0 \\ & & & & & \\ 5,3 & & 4,6 & & & 5,0\end{array}$

14 En contraposición, se notará en el mismo cuadro que las familias de las mujeres, cuyo carácter parcial en términos de funciones se señaló atrás, se componen principalmente de lineas de filiación (madres, hijas y niños de las hijas) que parecen igualmente incompletas, es decir, donde falta la figura del hombre adulto (padre, hijo adulto o yerno) y sus redes. Por otro lado, para los grupos domésticos dirigidos por hombres, cabe anotar que la tendencia señalada aquí parece ser la inversa cuando el status socio-profe- 
Estamos en presencia de la expresión familiar de las diferencias sociales. Se clasifica a las familias para hablar en realidad de grupos de status. ¿Expresan estas diferentes clases de familias, subculturas familiares de clase, se podría decir incluso estructuras familiares diferentes, como lo sugería Herbert Gans $(1982: 256)$ en un estudio urbano comparable? ${ }^{15}$. Llegar a una conclusión de este tipo supondría que existe una simple adecuación entre el grupo doméstico observado - que es una realidad efímera-y el espacio familiar - más virtual pero a la vez más amplio y durable que la unidad doméstica. Y, precisamente, las diferencias entre las tres clases de familia descritas anteriormente provienen, no de reglas de parentesco diferentes, sino de los cambios en la relación entre el parentesco y la residencia. Este lazo en el que las condiciones económicas juegan un rol importante, se traduce en diversos tipo de arreglos domésticos (familia extensa, familia nuclear simple o ampliada, familia parcial). En ellos se pueden señalar dos límites extremos. Dentro de la familia extensa, diversos segmentos derivados de agnados (siblings) forman hogares que viven en un mismo conjunto residencial referido al padre, quien ejerce un control sobre las residencias y sobre la red de relaciones locales de la familia. En el otro extremo, la familia parcial de mujeres (Azevedo 1966) es una unidad doméstica donde el funcionamiento y las relaciones remiten a un espacio familiar que supera ampliamente el marco de la casa. Entre estos dos tipos la relación entre el espacio familiar activo y los reagrupamientos residenciales reales se hace gradualmente más laxo, sin, por esto, desaparecer. En todos los casos, unos mismos valores y reglas de parentesco son compartidos, lo que permite a las diversas clases de familias entenderse dentro de un mismo código relacional. A pesar que el conjunto de las premisas de clasificación arriba presentadas muestra que la vida doméstica produce sentido y status, éstos últimos no están todavía definidos más que en términos relacionales, en la medida en que la vida doméstica no es nunca solitaria (incluso para los más desprotegidos) y en cambio si está de entrada insertada en el orden de los lazos entre las diversas clases de familias jerarquizadas.

sional se eleva y que, simultáneamente, los trabajadores asalariados en ascenso social se mudan del barrio. Es lo que se pudo verificar con relación a los asalariados de dos empresas petroquimicas. En estos casos, la familia nuclear predomina claramente en el grupo doméstico (agrupa 91,3\% del grupo). Es más, la presencia de la madre del jefe de familia y sus agregados disminuye de $8,5 \%$ a $5,2 \%$ cuando se pasa de los estratos inferiores a los estratos superiores de las empresas (Agier 1990:55).

15 Gans (1982:256-261) distinguía cuatro sub-culturas de clase a partir de sus diferencias familiares: las sub-culturas de la working class, de la lower class, de la middle class y de la professional upper middle class (la más individualista de todas). Bajo no pocos aspectos, su caracterización coincide con la caracterización de las diferentes clases de familia presentadas aquí. 


\section{ORDEN RELACIONAL Y CULTURA FAMILIAR}

El orden relacional pone en contacto a individuos, utilizando según los casos, los lazos, el lenguaje o los valores de las relaciones familiares. Se le describirá someramente distinguiendo dos formas principales de sociabilidad. Por un lado, las redes desarrolladas a partir de las relaciones familiares, que conforman un dominio en el cual predomina la intermediación femenina. Por otro lado, los grupos de pares (las turmas) compuestas esencialmente por hombres de una misma generación.

La cultura familiar forma el telón de fondo de los intercambios cotidianos en el barrio. A las relaciones estrictamente familiares se adicionan un conjunto de lazos que toman los mismos valores e incluso los términos propios de los lazos familiares. Fuera de los lazos de compadres y comadres, padrinos/madrinas y ahijados, establecidos por el bautismo de los niños y que comprometen a muchos parientes y no- parientes del vecindario, otras relaciones hacen extensivo un uso generoso de los términos de parentesco. Ese es el caso de los lazos llamados "de estimación" que utilizan el lenguaje de un lazo institucionalizado (parentesco, alianza, padrinazgo) para distinguir el carácter privilegiado de una amistad o de una dependencia: un amigo querido es un "hermano de estimación", un protector es "un padrino de estimación" etc. El uso de estos términos interviene también en la forma como se interpelan las personas del vecindario a quienes se les quiere manifestar una atención particular, al utilizar los títulos de hermano, ctiñado o compadre. Todo un código privado, y familiar se instaura en las relaciones internas del barrio. ¿Cuáles son los principales términos de este idioma familiar y cómo se construye el lugar central que allí ocupan las mujeres?

En todas las situaciones familiares y domésticas observadas en el barrio, el sistema de parentesco de referencia es bilateral con énfasis patrilineal: el nombre y el status familiar se transmiten en las líneas masculinas, siempre y cuando el hombre sepa "luchar" económicamente y socialmente para conservar su rol, definido por la figura social consensual de pai provedor. Es más, la incorporación de niños de crianza ${ }^{16}$ dentro de la casa y al margen de la familia nuclear, la acogida temporal o permanente de parientes agregados y, más aún la residencia común de varios segmentos de un mismo grupo de filiación (como lo practicaban comunmente los antiguos grupos de status intermedio y supe-

16 La criacão (colocación), muy extendida en el barrio, es distinta de la adopción oficial (ésta es muy rara). El niño criado tiene, en su unidad doméstica de acogida, un status inferior a los hijos de la familia. De otro lado, conserva su apellido original. 
rior de Bahía), son los modos familiares de formación de un status social construido alrededor del prestigio y del terreno social del hombre. Este peso simbólico del rol masculino explica una cierta tendencia a la uxorilocalidad ${ }^{17}$. Paralelamente, la socialización de las hijas jóvenes las incita a formarse como protectoras y organizadoras del hogar. Todo esto explica, de parte y parte, la fuerte influencia matrifocal en la vida doméstica. Para organizar la vida cotidiana de la unidad doméstica, se hace necesaria una capacidad femenina de intermediación (que no se confunde con un poder de decisión). Estos principios y las experiencias que conllevan, explican el que los requerimientos del grupo se busquen preferencialmente (y de manera "natural") del lado de las líneas maternas ${ }^{18}$. Esto puede verificarse, en particular, en el dominio del compadrio.

El padrinazgo de los niños es una forma de protección válida para toda la casa, y no sólo para el (o la) ahijado(a). Esta relación se crea, generalmente, cuando la familia nuclear, en su fase de constitución, tiene más necesidad de apoyo. Se pueden distinguir dos funciones de esta práctica: una, que se ha llamado hiper-parentesco, es un refuerzo estratégico de algunos de los lazos familiares existentes; la segunda es una función de cuasi-parentesco, que consiste en compensar un déficit de parentesco (un parentesco no muy cercano o poco eficaz) por medio de un acercamiento institucional de vecinos, colegas de trabajo o amigos. La primera de estas formas representa alrededor de un tercio de los bautizos y la segunda los dos tercios ${ }^{19}$. Estudiando, en la misma encuesta, el cuadro relacional donde se encuentran los padrinos y madrinas, se pudo observar una fuerte inclinación por el lado materno. Esta es muy importante en la escogencia de los padrinos parientes $(25,6 \%$ matrilinealmente, $5,1 \%$ patrilinealmente) y lo es aún más en la escogencia de los padrinos que no son parientes $(41 \%$ de relaciones por el lado de la madre, $17,9 \%$ por el lado del padre). Estas relaciones, extrafamiliares, provienen de los dominios residen-

17 Este es el caso, en particular, de las familias jóvenes, en proceso de constitución: se trata de no crear competencia, dentro de una misma residencia, entre dos hombres (el padre y el hijo) asumiendo los dos el mismo rol de jefe de hogar.

18 Esto es cierto para la mayoría de los servicios recibidos. En el caso de las unidades domésticas de presencia masculina, sin embargo, un único servicio es más frecuentemente solicitado por el lado de la línea paterna: el préstamo de dinero, del cual se puede pensar que compromete, más que los otros, una cuestión de honor para el hombre y para su linaje.

19 Estos resultados provienen de una encuesta en profundidad en una avenida del barrio. Las interpretaciones que de aqui se desprenden están más desarrolladas en Agier (1990b:52-56). 
ciales principalmente en el caso de las madre (vecindad de avenida) y profesionales en el caso del padre.

Esta competencia específica de las mujeres, definida dentro de la división de los roles familiares, explica también la manera como ellas ocupan el espacio del barrio. Su concentración en el referente doméstico se traduce en una presencia destacada en las avenidas. Este es su principal lugar de vida: allí tienen su casa, las casas de las amigas, comadres y parientes, el corredor y los umbrales donde se encuentran y charlan, el fondo de la avenida donde se lava y se extiende la ropa. Contrariamente a los hombres, la avenida es también un espacio de trabajo para las mujeres: esto incluye en primer lugar el mantenimiento de la casa, pero también su trabajo remunerado ${ }^{20}$. El cotidiano de la avenida es por consiguiente femenino; amistades que se tejen, rivalidades que aparecen, la convivencia cotidiana, los intercambios de servicios, las relaciones entre los niños que pasan de una casa a otra. Este dominio relacional y residencial femenino es también el sitio donde las mujeres buscan a sus padrinos y madrinas quienes van a ayudar a la familia, como se ha visto anteriormente. Pero su aptitud para reactivar estos lazos las obliga, cuando es el caso, a desprenderse del marco espacial del barrio que circunda las avenidas. De hecho, en situaciones ordinarias, si se ven mujeres en la plaza principal o en las calles del barrio, es porque eventualmente conversan en la entrada de las avenidas, y más frecuentemente porque pasan por esos lugares (o esperan el bus) para visitar, fuera del sector del barrio a una parienta o a una clienta. Su espacio urbano se define entonces por un conjunto cuyos términos claves podrian ser: avenida, familia, red. El discurso localista, cuando se apoya en la existencia de redes y de una cultura familiar compartida por todos, es más bien cosa de hombres.

Los hombres se identifican en un segundo dominio de sociabilidad, el de las turmas (bandas) o grupos de pares (Gans 1982), presentes y visibles particularmente en el espacio del barrio. Es dentro de las turmas que circulan las informaciones sobre los empleos o los servicios de trabajo para el negro. Pero son sobretodo el marco principal de la organización del esparcimiento: juegos de dominó, de damas o de cartas en los bares o en los andenes, salidas a la playa para jugar volibol o fútbol; organización de salidas en carro y picnic en las playas alejadas del litoral; organización de grupos de cuadrillas para las fiestas de San juan; formación de grupos de samba o de comparsas de carna-

20 Cuando tienen una actividad remunerada, las mujeres de las avenidas la llevan a cabo aún dentro del referente doméstico y familiar, aprovechando los saberes técnicos inculcados en su socialización: son empleadas de casa, lavanderas, costureras, nodrizas o auxiliares de jardines infantiles o de enfermería. 
$\mathrm{val}^{21}$. Se presentarán brévemente dos ejemplos: el de los equipos de fútbol permitirá observar los andamiajes estructurales de estas turmas; luego, el caso de la formación de una comparsa de carnaval nos informará sobre la acogida que tienen estos grupos.

En el sector objeto de nuestras encuestas, un pequeño terreno ocupa una parte de la plaza central. Es ahí que se organiza el campeonato de fútbol que agrupa alrededor de 300 participantes repartidos en quince equipos, cada uno compuesto por una veintena de miembros que se turnan a lo largo de todo el año según su disponibilidad. Nueve de estos equipos son del mismo sector, los otros seis vienen de otros puntos de Liberdade. La distribución de los participantes del campeonato según su sector de empleo muestra un componente importante de trabajadores del comercio y del transporte $(26 \%)$ y una parte igual de jóvenes con educación escolar y/o sin empleo, una parte menos importante pero significativa de asalariados de las nuevas industrias bahianas (polo petro-químico, CIA, Petrobrás, etc.: 18\%) y de trabajadores de servicios (mismo porcentaje) y finalmente una pequeña proporción de asalariados de industrias tradicionales $(5 \%$ ) y de la administración pública (mismo porcentaje). Estos equipos ofrecen entonces una imagen muy fidedigna de las diferentes categorías de trabajadores representadas en el barrio. Estas categorías se encuentran frecuentemente difuminadas en la vida de los grupos. Esto no significa que las diferencias sociales estén abolidas. Si se examina caso por caso la composición de los equipos, se ve por lo general la presencia dominante de un grupo salido de una misma familia (un núcleo de algunos hermanos y primos), de una misma empresa y/o de una misma avenida o callejuela. Esta presencia corresponde a los núcleos iniciales que han creado y caracterizado a los equipos, atrayendo enseguida hacia ellos a los vecinos y a los jóvenes del barrio (estudiantes y desempleados). Las diferencias en los ingresos, en los medios de acceso a los apoyos externos (un terreno para entrenar o la ayuda de una empresa o de un almacén para la compra de uniformes y de balones), crean matices discretos donde se reconocerá sin embargo, a quienes tienen una cierta estabilidad socio-profesional y a los otros, o el estado más o menos "equilibrado" o "necesitado" de las familias de procedencia ${ }^{22}$.

21 A propósito de este tema se deben mencionar dos estudios empíricos de referencia: Bacelar (1991) relata la experiencia, en Bahia, de la conquista por parte de los hombres de una invasión, de una cancha de fútbol enclavada en una zona de recreo reservada a la clase media. Magnani (1984) estudia, en la periferia de São Paulo, las redes y los espacios de recreo de los barrios populares.

22 Un estudio interesante de la presencia de las diferencias sociales globales en el "modelo jerárquico del baba" es el de Bacelar (1991:91-108). 
Al tiempo que se incorporan ciertos matices de posición social, los miembros de las turmas buscan idearse códigos, gustos y fronteras propias. Se ve esto en la abundancia (y algunas veces en el esoterismo para quienes no hacen parte) de los sobrenombres que sistemáticamente se pone a sus miembros (King, Manteiga, Maluco, Bebão, etc.) ${ }^{23}$ y a las turmas mismas ("Motivação", "Colher de peixe", "Zorra", "Zé Bigode de cerra e sua quadrilha"), o a los equipos de fútbol que ellas organizan ${ }^{24}$. También se le ve en el hecho que la inclusión de las mujeres, al margen del grupo, es asunto de las "primas y amiguitas". Se le ve finalmente en el hecho que cada grupo tiende a localizarse en un "rincón" preferido del barrio -un bar, la esquina de alguna de calle, el umbral de la casa de uno de los miembros del grupo, etc. - que se vuelve su sitio de citas, de discusión y de juego. Lo que se reproduce entonces es el equivalente al orden familiar, dado que los valores que se difunden en las relaciones del grupo se desprenden del funcionamiento de las familias y sus relaciones domésticas: fidelidad, generosidad, solidaridad, honor. Y así como sucede en las familias, estos valores alimentan de igual modo tanto las alianzas como los conflictos; son imposiciones que coaccionan al igual que solidaridades deseables.

Un último ejemplo, evocado brevemente aquí, nos pondrá en presencia de un grupo que cultiva al mismo tiempo los valores familiares y los valores locales. La comparsa carnavalesca Ilê Aiyê fue fundada en 1974 por jóvenes del barrio Liberdade. Habiendo ganado con el paso de los años una cierta imagen político-racial y cultural (una comparsa negra y africanista), se puede ver, examinando la composición de la turma que le dio origen, que esta comparsa fue ideada en una red de hermanos, primos, cuñados, compañeros de colegio y vecinos de barrio. La familia, la escuela y el barrio son los andamiajes sociológicos donde se inculcaron los códigos relacionales. Esto conforma todo un pequeño mundo de relaciones, como lo describe este breve aparte de una entrevista a uno de los fundadores de la comparsa:

23 Respectivamente Rey, Mantequilla, Loco, Bebedor.

24 La elección de los nombres de equipo de fútbol en el campeonato mencionado arriba, se hace dando rienda suelta a la imaginación de los fundadores y puede así revelar los marcos de preferencia caracteristicos de ciertos comportamientos sociales: el equipo "Dancing days" (título de una exitosa novela televisada) para los aficionados a las telenovelas, "Metálica futebol Clube" y "Crânio Metálico" para jóvenes aficiọnados de los grupos de rock de la ciudad que tienen esos nombres, "Vira copos" ("Voltea tos vasos) o "Papa água" ("bombeador de agua") para quienes aprecian, además del fútbol la camaradería masculina de los bares del barrio; etc. 
"La base [del Ilê Aiyê] eran personas de Liberdade. Así alrededor de la zona central, es decir, Curuzu. Todo por aqui, la mayoría era de por aquí. Curuzu. Progresso. No eramos muchos tipos. En realidad, la formación del Ilê se hizo mucho por la familia. Estábamos juntos, se hacía todo juntos. Entonces, algunos matrimonios salieron de ahí. Tres o cuatro matrimonios salieron de ahí

Era realmente un asunto de familia, un pequeño ghetto. Un grupo más o menos cerrado, donde poca gente de afuera del eje Liberdade-Curuzu tenía acceso. Después otras personas aparecieron, pero la coordinación general quedaba bien en nuestras manos.

Estaba el grupo llamado "colher de peixe" ("cuchara de pescado"). Se hacían fiestas, paseos. Muchos paseos. El San Juan, se hacía la fiesta juntos, teníamos todos los mismos vestidos, y en el carnaval recibiamos de regalo las mismas ropas. En esa época, era un época mucho mejor, se hacían paseos y además se daba de beber y de comer. Entonces se llegaba a hacer así grandes grupos, como el paseo que era organizado por nosotros, que era ...antiguamente se utilizaba un nombre de marca, era "la zorra ("el relajo") ataca de nuevo". Era "la zorra", ese era el grupo" (Apolónio de Jesus, fundador de la comparsa Ile Aiye).

Esta situación no tiene de hecho nada de excepcional. Mucho antes de que existieran las comparsas afro en Bahía, los grupos carnavalescos eran ya productos de la sociabilidad de los barrios, y este andamiaje urbano provocaba algunas veces rivalidades de barrio entre los diferentes grupos durante el carnaval.

El Ilê Aiyê se desarrolla bajo el doble signo de una cierta cultura familiar y de una apología de su lugar de origen. Por un lado, el origen familiar del grupo es regularmente recordado, e implica en este caso, a las mujeres madre, esposa y hermana - que rodeaban a los fundadores. Por otro lado, el grupo era presentado, en las sambas y en los discursos, como una sola familia, "la Familia Ilê". Por último, la participación de los adeptos se hacía muy ampliamente en familia: $75 \%$ están inscritos con sus padres (esposas, hijos, hermanos, primos) y se pudo encontrar que, desde 1988, las mujeres son relativamente más numerosas que los hombres entre los adeptos de la comparsa. Teniendo en cuenta la especialización femenina presente en las mediaciones familiares, de la que se habló anteriormente, este fenómeno puede ser considerado como una acentuación del carácter familiar de la comparsa. Paralelamente, la referencia al barrio, mantenida regularmente, va de la simple alegoría, que consiste en denominar el barrio y el sector con el nombre de origen de la comparsa (Liberdade, Curuzu), a la exaltación del sitio redefinido como territorio imaginario (quilombo) de la identidad y de la cultura negra. 


\section{DE LAS REDES AL LUGAR: LAS MEDIACIONES DE LA CULTURA URBANA}

Un lugar urbano puede ser definido de dos maneras. Visto desde el exterior se puede definir como una región moral, en el sentido que le da Robert Park. Es este nivel el que define los límites de los barrios, y sus caracterizaciones morales externas. Este nivel permite comprender las orientaciones de la movilidad residencial, la atracción que ejercen ciertas zonas en función de la distinción que ellas proveen, etc. Este sentido del lugar tiene a la ciudad entera como contexto de referencia. Es así como la ciudad de Salvador se puede hoy en día dividir según un modo simbólico dual, que distingue el lado de la bahía (antiguo y más pobre) y el lado de la orilla del mar (moderno y más rico); y en este contexto de interpretación, el barrio de Liberdade recibe una parte de su identidad del hecho de estar localizado del lado de la bahía. La dimensión dentro de la cual la ciudad es aprehendida en este caso es sociológica y geográfica.

La definición de sitio puede hacerse también desde el interior. Si se parte de la observación etnológica de las posiciones, redes e itinerarios urbanos de los individuos (entendidos como la primera unidad urbana de "pensamiento y de acción", según los términos de Park ya citados), se percibe que el individuo se vuelve urbano a través de una serie de mediaciones sociales. En Liberdade nos pareció que las redes familiares y cuasifamiliares por un lado, y los grupos de pares por otro lado, eran las principales formas de la mediación entre el citadino y la ciudad. En el caso de los grupos de pares con dominación masculina, estas formas no son necesariamente espaciales pero producen un apego o una cierta identificación con lugares que en Bahía se pueden denominar, la "zona" ("pedaço", el rincón ("canto"), la esquina, la cancha ("quadra") y finalmente el barrio ("bairro"), sin que haya jamás, dentro de estas definiciones émicas de la identidad y a pesar de la terminología espacial, un límite físico trazado con precisión. Se advierte sin embargo, un cierto gusto por una territorialidad más bien concentrada, centrípeta, y finalmente una preferencia por la identidad. En el caso de las sociabilidades femeninas, es el mantenimiento de buenas relaciones alrededor del grupo doméstico lo que nutre las preocupaciones cotidianas - hay que saber "entenderse bien con todo el mundo" dice una mujer de una avenida. Esto es lo que conduce a las mujeres a circular dentro de espacios más dispersos: en la avenida de residencia; de una avenida a otra; o a lo largo de las redes de parentela, de amigos o de clientes dentro y fuera del barrio. Cabría entonces preguntarse, partiendo de la cultura familiar y del andamiaje doméstico, si las mujeres del barrio 
no encarnarían las figuras sociales más centrifugas, mediadoras y abiertas a la alteridad. En una palabra si no son las más urbanas.

\section{BIBLIOGRAFIA CITADA}

AGIER, Michel

1990

Espaço urbano, família e status social. O novo operariado baiano nos seus bairros, Caderno CRH (Centro de Recursos Humanos, Salvador), $\mathrm{N}^{\circ}$ 13: 39-62, Salvador.

1990b O sexo da Pobreza. Homens, Mulheres e Famílias numa avenida em Salvador da Bahia", Tempo Social, Vol. 2, N.2:35-60. Universidade de São Paulo.

AMADO, Jorge 1982

Bahia de todos os Santos. Guia de ruas e mistérios, Rio de Janeiro, Record (primera edición 1945).

AUGÉ Marc

1992

Non-lieux. Introduction á une anthropologie de la surmodernité. París. Seuil.

1994 Pour une anthropologie des mondes contemporains. París. Fayard.

AZEVEDO, Thales de

1966 Família, casamento e divórcio. En Azevedo (ed) Cultura e situaçao racial no Brasil: 109-139. Rio, Civilização brasileira.

BACELAR, Jeferson

1991 Gingas e Nós: o jogo do lazer na Bahia. Salvador. Fundação Casa Jorge Amado (coleção Casa de Palavras).

BARNES, J.A.

1969 Networks and political process. En J. Clyde Mitchell (ed.), Social Networks in Urban Situations. Analyses of Personal Relationships in Central African Towns: 51-76. Manchester, Manchester University Press. 
BRANDÃO, Darwin y Motta e Silva

1958 Cidade do Salvador. Caminho do encantamento. São Paulo, Cia Ed. Nacional.

GANS, Herbert J.

1982 The Urban Villagers. Group and Class in the life of Italianamericans. New York, Free Press (primera edición 1962).

GRAFMEYER, Yves e Isaac Joseph

1979 La ville-laboratoire et le milieu urbain. En Grafmeyer y Joseph (eds.) L'École de Chicago: 5-52. París. Ed. du Champ Urbain.

HANNERZ, UIf

1983 Explorer la ville. Eléments d'anthropologie urbaine. París. Editions de Minuit.

JOSEPH, Isaac

1983 Les répertoires du citadin. Presentación del libro de Ulf Hannerz Explorer la vilie. Eléments d'anthropologie urbaine: 7-15. París. Editions de Minuit.

1984 Urbanité et ethnicité, Terrains, N³: 20-31.

1995 Le droit à la ville, la ville à l'oeuvre. Deux paradigmes de la recherche, Annales de la Recherche Urbaine, N64: 5-10.

LEWIS, Oscar

1963 Les enfants de Sanchez. Autobio-graphie d'une famille méxicaine. París. Gallimard.

1969 La Vida. une famille portoricaine dans une culture de pauvreté: San Juan et New York. París. Gallimard.

MAGNANI, José Guilherme C.

1984 Festa no pedaço. Cultura popular e lazer na cidade. São Paulo, Brasiliense. 
AITCHELL, J. Clyde

969 The concept and use of social networks. En J. Clyde Mitchell (ed.) Social Networks in Urban situations. Analyses of Personal Relationships in Central African Towns: 1-50. Manchester. Manchester University Press.

'ARK, Robert Ezra

926/1979 La communauté urbaine. Un modèle spatial et un ordre moral. En Grafmeyer, Yves e Isaac Joseph (eds) L'École de Chicago: 193-207. París. Ed. du Champ Urbain.

929/1979 La ville comme laboratoire social. En Yves Grafmeyer e Isaac Joseph (eds) L'École de Chicago: 163-179. París. Ed. du Champ Urbain.

2IBEIRO, Luis Cesar de Queiroz et Lago y Luciana Correa

994 Brésil: évolution métropolitaine y nouveaux modèles d'inegalité sociale, Problèmes d'Amérique latine, La documentation française, $\mathrm{N}^{\circ} 14: 269-281$.

IIMMEL, Georg

1908/1979 Disgressions sur l'étranger. En Yves Grafmeyer e Isaac Joseph (eds.) L'École de Chicago: 53-59. París. Ed. du Champ Urbain. 